\title{
BMJ Open Job burnout and turnover intention among Chinese primary healthcare staff: the mediating effect of satisfaction
}

\author{
Li Ran, ${ }^{1}$ Xuyu Chen, ${ }^{1}$ Shuzhen Peng, ${ }^{2}$ Feng Zheng, ${ }^{3}$ Xiaodong Tan (D) , ,4 \\ Ruihua Duan ${ }^{2}$
}

To cite: Ran L, Chen X, Peng S, et al. Job burnout and turnover intention among Chinese primary healthcare staff: the mediating effect of satisfaction. BMJ Open 2020;10:e036702. doi:10.1136/ bmjopen-2019-036702

- Prepublication history and supplemental material for this paper are available online. To view these files, please visit the journal online (http://dx.doi. org/10.1136/bmjopen-2019036702).

LR and XC contributed equally.

Received 02 January 2020

Revised 26 August 2020

Accepted 08 September 2020

\section{Check for updates}

(c) Author(s) (or their employer(s)) 2020. Re-use permitted under CC BY-NC. No commercial re-use. See rights and permissions. Published by BMJ.

${ }^{1}$ Department of Occupational and Environmental Health, School of Health Sciences, Wuhan University, Wuhan, China ${ }^{2}$ Department of Health Management, Huangpi People's Hospital, Wuhan, China

${ }^{3}$ Department of Health

Managment, Health Committee of Huangpi District of Wuhan, Wuhan, China

${ }^{4}$ School of Nursing, Wuchang University of Technology, Wuhan, China

\section{Correspondence to}

Dr Xiaodong Tan;

00300469@whu.edu.cn and Dr

Ruihua Duan;

854757230@qq.com

\section{ABSTRACT}

Objectives Although China has done a lot in strengthening the primary healthcare system, the high turnover intention is still a social problem to be reckoned with. The objective of this study is to explore the mediating effect of satisfaction between job burnout and turnover intention.

Design Cross-sectional study.

Methods A cross-sectional study was conducted to make sense of the job burnout, satisfaction and turnover intention among primary healthcare workers in central China. Structural equation modelling (SEM) was performed to study the mediating effect of satisfaction between job burnout and turnover intention with maximum likelihood estimation. The mediation effect test was carried out by using the bootstrap method.

Results SEM showed that job burnout was positively related to the turnover intention with the standard path coefficient of 0.845 (C.R. $=34.055, p<0.001$ ). The partial mediating effect of satisfaction was 0.047 , making up $5.32 \%$ of the total effect. The goodnessof-fit was acceptable (Goodness of Fit Index $=0.947$, Comparative Fit Index $=0.975$, root mean square error of approximation $=0.067$, Non-Normed Fit Index $=0.971$, Incremental Fit Index=0.975). Age, education level, monthly income, hire form and night shift were also found significantly correlated with turnover intention, and no difference was found between physicians and nurses. Conclusions The turnover intention is significantly affected by job burnout, satisfaction and demographical characteristics including age, education level, monthly income, hire form and night shift. Satisfaction can be regarded as a mediator between job burnout and turnover intention. Relative measures can be taken to promote enthusiasm and satisfaction thus decreasing the turnover rate.

\section{BACKGROUND}

Health and medical personnel play a seminal role in fulfilling the healthcare needs of the entire population; therefore, a robust allocation of human resources maintains the health system running smoothly and also guarantees people accessing to healthcare priority equally. ${ }^{1}$ Unfortunately, the current out of balance between healthcare staff supply and demand has challenged this priority and

\section{Strengths and limitations of this study}

- Structural equation modelling is adopted so that the qualitative and quantitative analyses can explore the relationship among job burnout, satisfaction and turnover intention.

- A multiple-group analysis was conducted between the physicians and nurses guaranteeing the applicability.

- This study summarises the influence demographical characteristics posed on the turnover intention among China's primary healthcare workers, enriching the study content.

- The reliability of structural equation modelling is repeatedly tested.

- Inability to accurately discuss the representativeness of the cross-sectional study.

triggered a global problem of continual brain drain. Up to 2013, the scarcity of healthcare workers (including physicians, nurses, and midwives) worldwide was estimated at 7.2 million, and it will sharply rising to 12.9 million by $2035 .^{2}$

As a developing country with a huge population, China's shortage of health workforce has posed one of the major obstacles to primary healthcare services. According to the China health statistics yearbook, there are only 0.46 paediatricians per 1000 children, much lower than the goal number of 2.06 per 1000 children. Equally consistent is the finding that the number of anaesthesiologists per 10000 people is less than 0.65 , while the number in some developed countries in Europe is 2.5-3. ${ }^{3}$ To make matters worse, primary healthcare workers are generally confronted with the challenge of high turnover intention, which has become a social problem to be reckoned with. ${ }^{4}$ Results of a survey show that from 2010 to 2016 , the proportion of Chinese primary healthcare staff decreased from $44 \%$ to $33 \% .^{5}$ Moreover, the average turnover rate of nurses in first-class tertiary hospitals is $5.8 \%$ in China, which goes up to $8 \%-10 \%$ in economically 

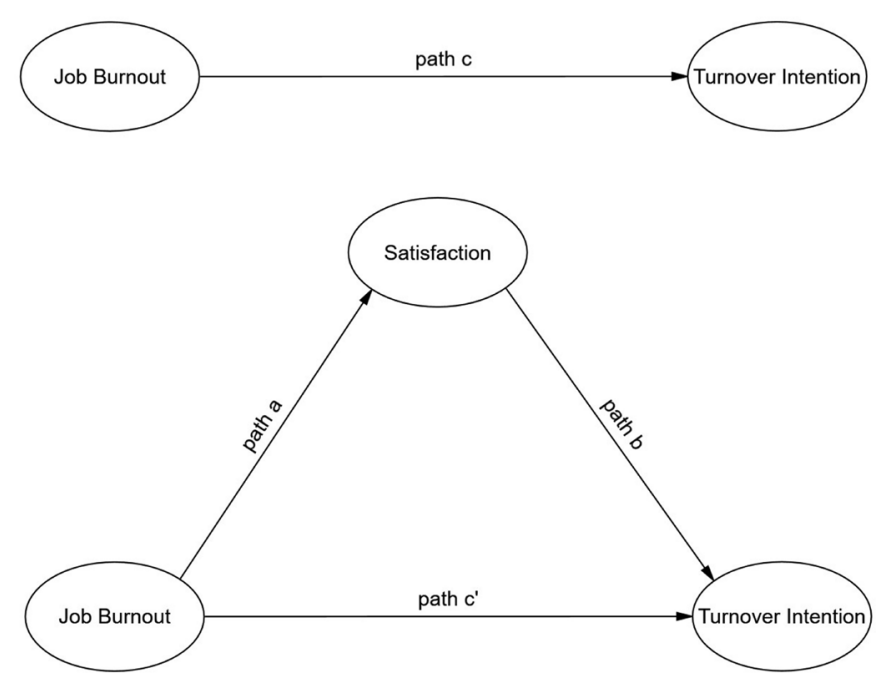

Figure 1 Hypothesised model of burnout, satisfaction and turnover intention.

advanced regions like Shanghai and Guangzhou. ${ }^{6}$ Under this circumstance, the turnover intention has been an important and popular study subject in psychology and management field.

Turnover intention reflects an individual's conscious and deliberate willfulness to quit one's job or organisation within a certain period, which would possibly pose a major problem in healthcare system resulting in a high turnover rate. ${ }^{7-9}$ That is to say, the turnover intention is the strongest cognitive precursor of turnover, directly affecting the choice of departure. Because of a considerable number of predictive modelling formulas of voluntary turnover has been established, researchers generally recognised and supported that several hypothesised variables are associated with the intention to leave, involving commuting stress, emotional intelligence, job stress, job burnout and job satisfaction. ${ }^{10-13}$ Among the hypothesised linkages above, job burnout and satisfaction are the most common proposed antecedents.

In the late 1980s, Pines and Aronson defined job burnout as a state of physical, emotional and mental exhaustion. ${ }^{14} 15$ It describes the individuals' psychological response to prolonged interpersonal and chronic emotional stressors, dominantly caused by a long-term involvement in emotionally demanding situations. ${ }^{16}$ Job burnout can be categorised into three dimensions, including emotional exhaustion, depersonalisation and the sense of reduced personalised accomplishment. Looking from the former researches, job burnout has a strong positive relationship with turnover intention whereas a negative relation with job satisfaction. ${ }^{1718}$ Job satisfaction encompasses employees' feelings and thoughts about various aspects of their job. In other words, job satisfaction refers to an individual's cognitive or effective evaluation of his or her occupational duties, presenting the extent people like the job and reflecting the effective judgements people hold toward their work condition. ${ }^{19}{ }^{20}$ Numerous studies have repeatedly verified that job satisfaction is inversely related to turnover and intent to leave. In addition to direct effects, we propose that job satisfaction serves as a mediator through which job burnout affects turnover intention as well. Yet, there is still a lack of literature supporting our hypothesis; hence, it is necessary to conduct this study to make up the gap.

Taken together, the theoretical framework used in this study originated from researches suggesting that turnover intention maybe both related to satisfaction and burnout toward the job. Accordingly, we hypothesised that:

H1: Job burnout is positively related to turnover intention.

H2: Job satisfaction is negatively related to turnover intention.

H3: Job satisfaction is negatively related to job burnout.

H4: Job satisfaction has a mediating effect between job burnout and turnover intention.

As shown in figure 1, we tested this theoretical model with the data from primary healthcare staff in central China to explore the mediating effect of satisfaction.

\section{METHODS}

\section{Design and sample}

In this investigation, we used survey research methods to make sense of the job burnout, satisfaction and turnover intention of primary healthcare staff. From March to May 2019, a cross-sectional study was conducted in Huangpi District of Wuhan in central China. The sample size was estimated with the average detection rate of burnout in China with the equation: $n=Z_{(\alpha / 2)}^{2} \times p \times(1-p) / \delta^{2}$, where $\alpha$ is $0.05, \delta$ is 0.08 and $p$ is $55 \%$. To compensate for the non-response rate, the sample was increased by $10 \%$ with a final sample size of 540. Participants involved met the following inclusion criteria: (1) working for at least 6 months and (2) being volunteered to participate in the survey. All participants were recruited face-to-face from 29 primary healthcare institutions in Huangpi district by our research group. Participants fulfilled electronic questionnaires with a mobile application or they orally answered questions and the results were synchronously typed in. The study data were anonymous to protect privacy. The questionnaire comprised following sections: sociodemographic information, job satisfaction, job burnout and turnover intention (see detail in online supplemental appendix).

\section{Methods of measurement Job satisfaction}

On the bases of the local actual condition, we collected the job satisfaction information using an Adjusted Satisfaction Scale. The adjusted scale referred for the Minnesota Satisfaction Questionnaire, ${ }^{21}$ Job Satisfaction Survey ${ }^{22}$ and Job Descriptive Index, ${ }^{23}$ including 14 items (items 1-14) about the satisfaction with the internal environment, external environment, remunerations, management and work itself. Participants responded to a 5-point Likert Scale ranging from 1 point (the most unsatisfaction) to 5 
points (the most satisfaction). A higher score indicates a higher satisfaction.

\section{Job burnout}

The information on participants' job burnout was gathered with an adjusted 5-point Likert Burnout Scale according to the Maslach Burnout Inventory-General Survey developed by Maslach and Jackson. ${ }^{24}$ Several emotion-related items were used to describe participants' burnout experience, including 'I'm interested in my job' (item 15, reverse coded), 'I'm fit for this job' (item 16, reverse coded), 'I think my work is challenging' (item 17), 'My work is heavy' (item 18), 'I think my work is meaningless' (item 19), 'I can't find personal accomplishment in my job' (item 20), 'I feel exhausted' (item 21), 'I'm indifference of my job' (item 22) and 'I feel anxious and fretful' (item 23). A higher score indicates a greater propensity for job burnout.

\section{Turnover intention}

The turnover intention was similarly measured with an adjusted scale concerning several plan-related items. The adjusted scale referred for a six-item version of the Turnover Intention Scale (TIS-6) explored by Griffeth. ${ }^{25}$ The items include 'I once thought to leave my current organization' (item 24), 'I shall likely seek a new job within the next year' (item 25), 'I shall accept a new job if I have a chance' (item 26), 'I consider that the employment situation is favorable' (item 27) and 'I can find a good job' (item 28). The above items were evaluated with a 5-point Likert Scale, where 1 represents strongly disagree, 2 represents disagree, 3 represents slightly disagree, 4 represents agree and 5 represents strongly agree.

\section{Statistical analysis}

All statistical analyses and hypothesis testing were performed using SPSS V.22.0 and Analysis of Moment Structure (AMOS) V.21.0, with two-sided tests. In the first stage, an empirical study was processed to optimise items in each scale, including discrimination tests and collinearity diagnostics. Then, an exploratory factor analysis (EFA), confirmatory factor analysis (CFA) and a Cronbach's $\alpha$ coefficient method were applied to check the discriminant validity and reliability of above-mentioned scales. In the next stage, the Pearson product-moment correlation coefficients were calculated to analyse the correlations between variables. Last, the effect of job burnout on turnover intention via satisfaction was examined using a structural equation modelling with maximum likelihood estimation. The mediation effect test was carried out by using the bootstrap method. The goodness-of-fit of the model was evaluated with $\chi^{2}$ statistic, the Goodness of Fit Index (GFI), the Comparative Fit Index (CFI), the root mean square error of approximation (RMSEA), the Non-Normed Fit Index (NNFI) and the Incremental Fit Index (IFI).
The model fitted well when GFI>0.90, CFI 0.90, RMSEA $<0.05$, NNFI $>0.90$ and $I F I>0.90$.

\section{Patient and public involvement}

Participants were not involved in development of the research question and outcome measures, study design or conduct of this study.

\section{RESULTS}

\section{Profile of sample}

A total of 1300 electronic questionnaires were sent out, and 1279 eligible participants left after deleting those with uncompleted or suspected unreal answers. The effective rate is $98.38 \%$. As shown in table 1 , over half of the participants $(66.50 \%)$ were women; $79.12 \%$ were married; $43.55 \%$ were physicians and $41.83 \%$ were nurses; $63.02 \%$ earned 2001-4000 Chinese Renminbi (RMB, US\$290.97-581.65) per month. The most frequent occupational title was junior tile (accounting for $46.76 \%$ ) and the most frequent education level was separately undergraduate degree and above (accounting for $47.46 \%$ ) and junior college degree (accounting for $37.06 \%)$. The prevalence rate of satisfaction, job burnout and turnover intention was separately $79.99 \%$, $18.69 \%$ and $26.04 \%$. The median (range) score of satisfaction, job burnout and turnover intention was 52 (13-65), 22 (9-37), and 12 (5-25).

\section{Tests of the hypothetical model}

\section{Reliability and validity analysis}

Before reliability analysis and validity analysis, we applied discrimination tests and collinearity diagnostics to filter optimal items. Although the Adjusted Satisfaction Scale yields high indices of discrimination, there exists strong collinearity from items 1 to 7 , item 12 and item 13 . After all comprehensive considerations, we deleted relative items except item 1. The Cronbach's $\alpha$ of this scale reaches 0.956 , indicating satisfactory reliability. Moreover, the modified scale construction is effective measuring by EFA (Kaiser-Meyer-Olkin=0.928, $\mathrm{p}<0.001$ ) and suitable for CFA. The model finally fits the data acceptably $(\chi 2 / d f$ $=7.889$, GFI $=0.986, C F I=0.994, R M S E A=0.073, N N F I=0.994$, IFI $=0.994)$.

In the Adjusted Burnout Scale, we omitted the items from 15 to 17,19 and 21 because of a low distinguishability in discriminant analysis. Cronbach's $\alpha$ of this scale was increasing to 0.802 . Besides, the adjusted burnout also has a good validity conducted by EFA and CFA $(\chi 2 / d f$ $=8.395$, GFI $=0.993, C F I=0.994$, RMSEA $=0.076, N N F I=0.994$, IFI=0.994).

Similar in the adjusted TIS, item 27 was removed. The Cronbach's $\alpha$ coefficient for the remaining four items $(\alpha=0.865)$ indicated good internal consistency reliability. And the validity is acceptable $(\chi 2 / d f=6.889, G F I=0.948$, CFI=0.973, RMSEA=0.067, NNFI=0.969, IFI=0.973).

\section{Correlation analysis}

Table 2 demonstrates the means, SD and correlation coefficients among three dimensions of job satisfaction, burnout 
Table 1 Description of the respondents $(n=1279)$

\begin{tabular}{|c|c|c|c|c|c|c|c|}
\hline \multirow[b]{2}{*}{ Variables } & \multirow[b]{2}{*}{$\mathbf{N}(\%)$} & \multicolumn{2}{|l|}{ Satisfaction } & \multicolumn{2}{|c|}{ Job burnout } & \multicolumn{2}{|c|}{ Turnover intention } \\
\hline & & $\begin{array}{l}\text { Prevalence } \\
\text { rate }(\%)\end{array}$ & $\chi^{2}$ & $\begin{array}{l}\text { Prevalence } \\
\text { rate (\%) }\end{array}$ & $\chi^{2}$ & $\begin{array}{l}\text { Prevalence } \\
\text { rate }(\%)\end{array}$ & $\chi^{2}$ \\
\hline Sex & & & 0.016 & & 3.233 & & 2.328 \\
\hline Male & $429(33.50)$ & 26.9 & & 7.19 & & 9.62 & \\
\hline Female & $850(66.50)$ & 53.09 & & 11.5 & & 16.42 & \\
\hline Age (years) & & & $13.853^{\star *}$ & & $33.398^{\star \star}$ & & $55.014^{\star \star}$ \\
\hline$\leq 30$ & $380(29.71)$ & 23.31 & & 7.74 & & 10.48 & \\
\hline $31-40$ & $366(28.62)$ & 21.5 & & 5.79 & & 8.99 & \\
\hline $41-50$ & 436 (34.09) & 28.46 & & 4.85 & & 5.94 & \\
\hline$\geq 51$ & $97(7.58)$ & 6.72 & & 0.31 & & 0.63 & \\
\hline Occupation & & & 2.562 & & 3.045 & & 3.698 \\
\hline Physician & 557 (43.55) & 34.4 & & 8.29 & & 12.28 & \\
\hline Nurse & $535(41.83)$ & 34.09 & & 7.27 & & 10.63 & \\
\hline Specialists in laboratory medicine & $89(6.96)$ & 5.71 & & 1.72 & & 1.41 & \\
\hline Public health physician & $65(5.08)$ & 3.83 & & 0.86 & & 1.17 & \\
\hline Pharmacist & $33(2.55)$ & 1.95 & & 0.55 & & 0.55 & \\
\hline Educational level & & & 4.146 & & 7.692 & & $23.072^{\star *}$ \\
\hline Junior school and below & $16(1.25)$ & 0.94 & & 0.31 & & 0.39 & \\
\hline High school/technical school & $182(14.23)$ & 11.73 & & 1.8 & & 1.88 & \\
\hline Junior college degree & $474(37.06)$ & 30.34 & & 6.57 & & 9.23 & \\
\hline Undergraduate degree and above & $607(47.46)$ & 36.98 & & 10.01 & & 14.54 & \\
\hline Marital status & & & 8.618 & & $13.308^{\star}$ & & $26.538^{\star *}$ \\
\hline Married & $1012(79.12)$ & 64.12 & & 13.29 & & 18.22 & \\
\hline Unmarried & $227(17.75)$ & 13.76 & & 4.77 & & 6.96 & \\
\hline Divorced/Widowed & $40(3.13)$ & 2.11 & & 0.63 & & 0.86 & \\
\hline Technical post title & & & 8.8 & & 7.039 & & 4.691 \\
\hline No title & $286(22.36)$ & 18.45 & & 4.53 & & 6.25 & \\
\hline Junior title & $598(46.76)$ & 36.75 & & 9.23 & & 12.9 & \\
\hline Intermediate title & $288(22.52)$ & 17.36 & & 4.07 & & 5.16 & \\
\hline Senior title & $107(8.36)$ & 7.43 & & 0.86 & & 1.73 & \\
\hline Monthly income (RMB) & & & $16.713^{\star *}$ & & $12.166^{\star}$ & & $19.817^{\star *}$ \\
\hline$\leq 2000$ & $71(5.55)$ & 3.99 & & 1.25 & & 2.19 & \\
\hline $2001-3000$ & 339 (26.51) & 19.55 & & 6.18 & & 8.61 & \\
\hline $3001-4000$ & $467(36.51)$ & 30.18 & & 6.25 & & 8.05 & \\
\hline $4001-5000$ & $266(20.80)$ & 17.51 & & 2.74 & & 4.69 & \\
\hline$\geq 5001$ & $136(10.63)$ & 8.76 & & 2.27 & & 2.5 & \\
\hline Hire from & & & 5.467 & & $9.631^{*}$ & & $19.637^{\star *}$ \\
\hline Personnel agent staff & $171(13.37)$ & 52.15 & & 10.63 & & 14.78 & \\
\hline Permanent staff & $825(64.50)$ & 9.93 & & 3.45 & & 5.08 & \\
\hline Contract staff & $173(13.53)$ & 10.87 & & 2.58 & & 3.29 & \\
\hline Temporary staff & $110(8.60)$ & 7.04 & & 2.03 & & 2.89 & \\
\hline Working time (hours/week) & & & $30.865^{\star *}$ & & $34.103^{\star \star}$ & & $37.055^{\star *}$ \\
\hline$\leq 30$ & $15(1.17)$ & 0.78 & & 0.39 & & 0.47 & \\
\hline $31-40$ & $629(49.18)$ & 41.91 & & 6.25 & & 9.38 & \\
\hline $41-50$ & 427 (33.39) & 26.19 & & 7.35 & & 9.93 & \\
\hline
\end{tabular}

Continued 
Table 1 Continued

\begin{tabular}{|c|c|c|c|c|c|c|c|}
\hline \multirow[b]{2}{*}{ Variables } & \multirow[b]{2}{*}{ N (\%) } & \multicolumn{2}{|l|}{ Satisfaction } & \multicolumn{2}{|l|}{ Job burnout } & \multicolumn{2}{|c|}{ Turnover intention } \\
\hline & & $\begin{array}{l}\text { Prevalence } \\
\text { rate (\%) }\end{array}$ & $\chi^{2}$ & $\begin{array}{l}\text { Prevalence } \\
\text { rate (\%) }\end{array}$ & $\chi^{2}$ & $\begin{array}{l}\text { Prevalence } \\
\text { rate (\%) }\end{array}$ & $\chi^{2}$ \\
\hline$\geq 51$ & $208(16.26)$ & 11.11 & & 4.69 & & 6.25 & \\
\hline Working years & & & $13.485^{\star *}$ & & $26.683^{* *}$ & & $44.637^{\star \star}$ \\
\hline $1-5$ & $326(25.49)$ & 20.17 & & 6.57 & & 8.99 & \\
\hline $6-10$ & 202 (15.79) & 11.57 & & 3.21 & & 5.39 & \\
\hline $11-15$ & $115(8.99)$ & 7.04 & & 1.95 & & 2.51 & \\
\hline $16-20$ & $201(15.72)$ & 12.28 & & 3.05 & & 3.68 & \\
\hline$\geq 21$ & 435 (34.01) & 28.93 & & 3.91 & & 5.47 & \\
\hline Night shift & & & 3.406 & & $18.827^{\star *}$ & & $17.374^{\star \star}$ \\
\hline 0 & 769 (60.13) & 49.02 & & 9.07 & & 13.21 & \\
\hline $1-3$ & $471(36.83)$ & 28.46 & & 8.6 & & 11.65 & \\
\hline$>3$ & 39 (3.04) & 2.51 & & 1.02 & & 1.18 & \\
\hline Total & $1279(100)$ & 79.99 & - & 18.69 & - & 26.04 & - \\
\hline
\end{tabular}

Notes: ${ }^{*} \mathrm{p}<0.05,{ }^{* *} \mathrm{p}<0.01$.

RMB, Renminbi.

and turnover intention. As is indicated that job satisfaction has both a significant negative relation with turnover intention $(r=-0.414, \mathrm{p}<0.001)$ and job burnout $(r=-0.387$, $\mathrm{p}<0.001)$, job burnout showed a significant positive correlation with turnover intention $(r=0.797, \mathrm{p}<0.001)$.

Structural equation model

As can be seen in figure 2 and table 3 , three latent variables in the model were significantly intercorrelated. The standardised path coefficient of path a (Job burnout $\rightarrow-$ Satisfaction), b (Satisfaction $\rightarrow$ Turnover intention) and c' (Job burnout $\rightarrow$ Turnover intention) was respectively $-0.409 \quad$ (C.R. $=-14.298, \quad \mathrm{p}<0.001),-0.116 \quad$ (C.R. $=-6.023$, $\mathrm{p}<0.001)$ and 0.845 (C.R. $=34.055, \mathrm{p}<0.001)$. Higher standardised path coefficients suggest stronger correlations, with values over 0.200 considered very correlated. Taken

Table 2 Pearson correlation among job satisfaction, burnout and turnover intention of primary healthcare workers

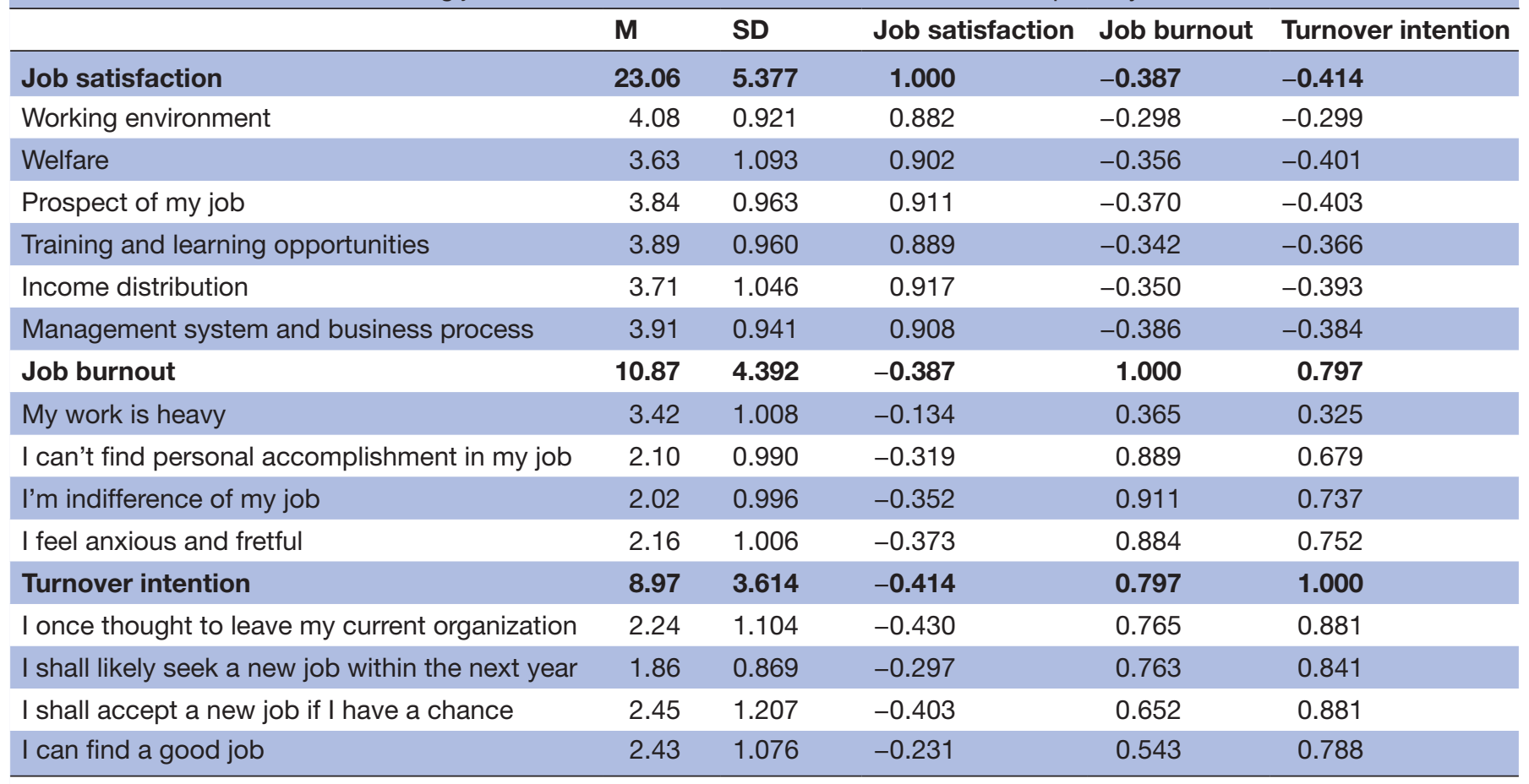

All $P_{\mathrm{s}}<0.01$. M, mean value. 


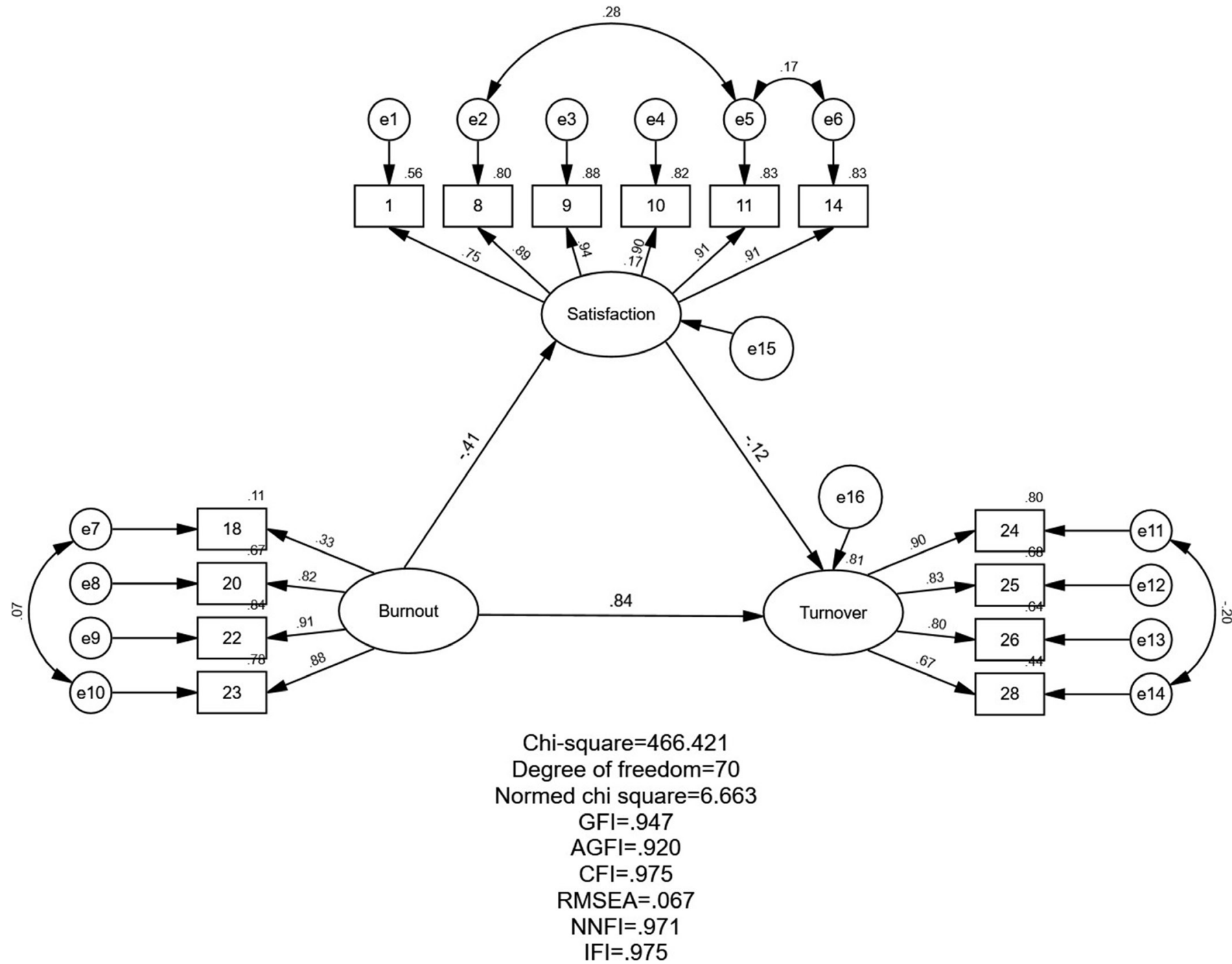

Figure 2 The structural equation modelling for the hypothetical model. AGFI, adjusted goodness of fit index; CFI, Comparative Fit Index; GFI, Goodness of Fit Index; IFI, Incremental Fit Index; NNFI, Non-Normed Fit Index; RMSEA, root mean square error of approximation.

path a as an example, it means that for each one SD decreases in the job burnout, the change in satisfaction will increase by $0.409 \mathrm{SD}$. The mediating effect of satisfaction was significant $(\mathrm{p}<0.001)$ with the path coefficient of 0.047 , making up $5.32 \%$ of the total effect (proportion $=\mathrm{a} \times \mathrm{b} / \mathrm{c}, 0.409 \times 0.116 / 0.892=0.053)$. The hypothetical model yields satisfactory values $(G F I=0.947, C F I=0.975$, $R M S E A=0.067, N N F I=0.971, I F I=0.975)$, indicating credible data fit.
Variables such as age, education, income and so on were introduced in the model to further research on the influences. Figure 3 illustrates the standardised path coefficient between each variable. Educational level, monthly income and hire form showed a direct $(r=0.084,-0.037$, 0.048 , respectively) and indirect $(r=-0.008,-0.018,-0.015$, respectively) effect on turnover intention. Also, age and nigh shift could affect turnover intention through job burnout with the standard path coefficient of -0.111

\section{Table 3 The standard effects in the hypothetical model}

\begin{tabular}{llcccrr}
\hline $\begin{array}{l}\text { Endogenous } \\
\text { variables }\end{array}$ & $\begin{array}{l}\text { Exogenous } \\
\text { variables }\end{array}$ & Estimate & C.R. & Direct effect $(\mathbf{p})$ & Indirect effect $(\mathbf{p})$ & Total effect $(\mathbf{p})$ \\
\hline Turnover intention & Burnout & 0.845 & 34.055 & $0.845(<0.001)$ & $0.047(<0.001)$ & $0.892(<0.001)$ \\
& Satisfaction & -0.116 & -6.023 & $-0.116(<0.001)$ & - & $-0.116(<0.001)$ \\
Satisfaction & Burnout & -0.409 & -14.298 & $-0.409(<0.001)$ & - & $-0.409(<0.001)$ \\
\hline
\end{tabular}

C.R., critical ratios. 


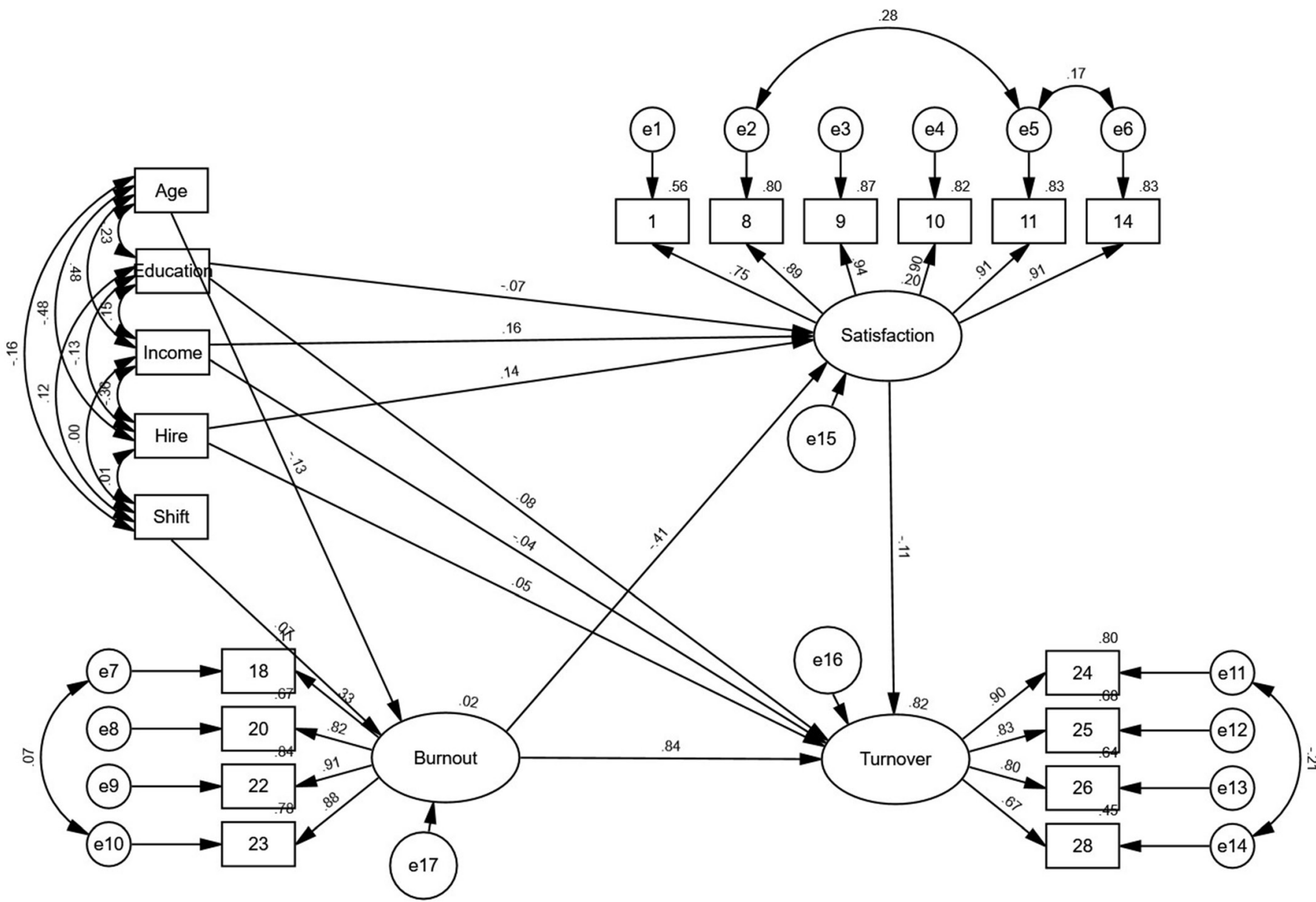

Chi-square $=631.423$

Degree of freedom $=132$

Normed chi square $=4.784$

GFI=.947

AGFI $=.924$

$\mathrm{CFI}=.971$

RMSEA $=.054$

$\mathrm{NNFI}=.963$

IFI $=.971$

Figure 3 The structural equation modelling after introducing demographic characteristic. AGFI, adjusted goodness of fit index; $\mathrm{CFI}$, Comparative Fit Index; GFI, Goodness of Fit Index; IFI, Incremental Fit Index; NNFI, Non-Normed Fit Index; RMSEA, root mean square error of approximation.

and 0.062. This model also showed a good fit to the data: $G F I=0.947, C F I=0.971, R M S E A=0.054$, NNFI $=0.963$, IFI $=0.971$.

To further deal with the stability of the model, a multiple-group analysis was conducted between physicians and nurses. Table 4 summarises the testing for invariant factorial structure between physicians and nurses. The $\mathrm{p}$ values of the model of measurement weights and structural weights were separately 0.35 and 0.39 , confirming the stability. Although p values were lower than 0.05 in the model of structural covariances, structural residuals and measurement residuals, incredibly small variations were presented in indices of fit (all variations change $<0.05)$. Therefore, the model can be regarded as stable in physicians and nurses.

\section{DISCUSSION}

This study was conducted to investigate the mediating effect of job satisfaction in the relationship between job burnout and turnover intention among primary medical staff in Huangpi District where the medical resources and clinical ability represent the averaged level in China. Through it, we confirmed the direct influence of job burnout and satisfaction drew on the turnover intention and the mediating effect of satisfaction. Our study additionally demonstrated that the prevalence rate of job burnout and turnover intention was, respectively, 18.69\% and $26.04 \%$. The results are quite consistent with previous researches in China. ${ }^{26} 27$

In line with earlier studies, our results recognised that job burnout positively predicted turnover intention with an 
Table 4 Testing for invariant factorial structure of a measuring instrument

\begin{tabular}{|c|c|c|c|c|c|c|c|c|c|c|}
\hline Model & Delta- $x^{2}$ & $\begin{array}{l}\text { Delta- } \\
\text { df }\end{array}$ & $P$ value & $\begin{array}{l}\text { Delta- } x^{2} \\
\text { /df }\end{array}$ & $\begin{array}{l}\text { Delta- } \\
\text { GFI }\end{array}$ & $\begin{array}{l}\text { Delta- } \\
\text { AGFI }\end{array}$ & $\begin{array}{l}\text { Delta- } \\
\text { NFI }\end{array}$ & $\begin{array}{l}\text { Delta- } \\
\text { RFI }\end{array}$ & $\begin{array}{l}\text { Delta- } \\
\text { IFI }\end{array}$ & Delta-TLI \\
\hline $\begin{array}{l}\text { Measurement } \\
\text { weights }\end{array}$ & 12.207 & 11 & 0.35 & 0 & 0.003 & -0.001 & 0.002 & 0 & 0.002 & 0 \\
\hline Structural weights & 23.296 & 22 & 0.39 & -0.001 & 0.005 & -0.002 & 0.003 & 0 & 0.003 & 0 \\
\hline $\begin{array}{l}\text { Structural } \\
\text { covariances }\end{array}$ & 95.617 & 36 & $<0.05$ & -0.007 & 0.003 & -0.006 & 0.001 & -0.003 & 0.001 & -0.003 \\
\hline $\begin{array}{l}\text { Measurement } \\
\text { residuals }\end{array}$ & 196.600 & 53 & $<0.05$ & -0.015 & -0.003 & -0.012 & -0.002 & -0.008 & -0.002 & -0.008 \\
\hline
\end{tabular}

AGFI, adjusted goodness of fit index; GFI, Goodness of Fit Index; IFI, Incremental Fit Index; NFI, normed fit index; RFI, relative fit index; TLI, Tucker-Lewis coefficient.

explanatory power of $94.73 \% .{ }^{11}$ For job burnout and its four latent measures, 'no personal accomplishment', 'indifference' and 'anxious and fretful' show a strong correlation with burnout except for 'a heavy work'. It is generally believed that burnout is intrinsically related to work factors and second to personality factors. ${ }^{28}$ Hence, hospital managers must think about the role conflict and the way to solve emotional exhaustion and reduced personalised accomplishment. Our results also found that satisfaction could directly or indirectly affect turnover intention with a relatively limited effect. This finding helps to illuminate the relations among burnout, satisfaction and turnover that were not apparent before, as most previous studies focused on satisfaction's direct impact on turnover instead of a mediator. ${ }^{29}{ }^{30}$ Seen from the partial mediating effect of satisfaction, job burnout, to a very small degree, would increase the turnover tendency by reducing the satisfaction levels. That is to say, the fundamental reason for turnover tendency is job burnout while only $5.32 \%$ is related to low satisfaction. Therefore, the improvement of working conditions, welfares, advanced-learning opportunities and reward mechanisms is worthy of concern but limited effect. The effective ways to solve this problem are to understand how burnout generates, focus on staff's physical and mental changes, and do in science.

Apart from it, the turnover intention was noted to be affected by age, education level, monthly income, hire form and night shift directly or through the mediators of satisfaction and burnout in our study. This influence shows no difference between physicians and nurses. Primary healthcare institutions generally play an essential role in medical providing and safeguarding among the broadest masses of people. In past decades, the medical quality and service standard in primary medical institutions were continually enhanced with the in-depth development of national medical and health system reform. But most of the basic healthcare staff in China still encounter low salaries, less independence, insufficient social support and few promotion prospects, which could lead to job burnout, unsatisfaction even turnover. ${ }^{31}{ }^{32}$ To fully use health resources and to improve the healthcare system's overall social impacts, governments and concerned departments should emphasise more attention to optimise medical resources allocation. ${ }^{33}$ Under market economy conditions, public hospital managers should also establish and consummate hospital operation and management systems. As an occupation with high risk, pressure and skill, healthcare staffs deserve a high payment. However, there is a huge income gap between China and developed countries. ${ }^{34}$ The average monthly salary of Chinese health workers in 2017 was about 6669 RMB (approximately US\$969.54). ${ }^{35}$ It is necessary to adopt a reasonable mechanism of performance incentive and financial management, to regulate and optimise nigh-shift works, and to set up a good academic atmosphere at the same time. Besides, more focuses need to raise on healthcare providers' psychological states, especially those youth with high educational background and academic qualification. In this way, the employee's motivation and enthusiasm could be improved to some extent.

Although this study contributes to the knowledge base of the turnover intention related to job burnout and satisfaction, it does have several limitations. First, causal relationships among turnover, burnout and satisfaction should be cautiously interpreted as this is a cross-sectional study. Second, despite the credible reliability and validity, the scales we used were adjusted based on the existing general scales. Hence, it needs to be tested and replicated with additional researches. Third, other potential predictors such as work stress, social support and mental health were not captured in our questionnaire. We will continue this study in the future to overcome the shortages.

\section{CONCLUSION}

The current findings indicate a positive association between job burnout and turnover intention, while a negative relation between job burnout and 
satisfaction, as well as satisfaction and turnover intention. Also, satisfaction can be regarded as a mediator between job burnout and turnover intention, whose partial mediating effect is $5.32 \%$. Age, education level, monthly income, hire form and night shift also influence the turnover intention, hence, relative measures can be taken to promote enthusiasm and satisfaction thus decreasing the turnover rate.

Acknowledgements The authors are thankful to all the healthcare staff participated in this study. They are also grateful to all the investigators for collecting and calculating data.

Contributors Conceived and designed this paper; wrote this paper: LR. Calculated data: LR, XC, SP and FZ. Performed the study and collected data: XC and LR. Provided with analysis tools: XT. Mended and approved the final version: XT and RD.

Funding The authors have not declared a specific grant for this research from any funding agency in the public, commercial or not-for-profit sectors.

Competing interests None declared.

Patient consent for publication Not required.

Ethics approval and consent to participate Ethical approval for this study was granted by the Research Ethics Boards of Wuhan University (No.2018YF0080). Informed consent was obtained from all survey participants.

Provenance and peer review Not commissioned; externally peer reviewed.

Data availability statement Data are available upon reasonable request. Data may be made available by contacting the corresponding author.

Open access This is an open access article distributed in accordance with the Creative Commons Attribution Non Commercial (CC BY-NC 4.0) license, which permits others to distribute, remix, adapt, build upon this work non-commercially, and license their derivative works on different terms, provided the original work is properly cited, appropriate credit is given, any changes made indicated, and the use is non-commercial. See: http://creativecommons.org/licenses/by-nc/4.0/.

ORCID iD

Xiaodong Tan http://orcid.org/0000-0002-2802-5547

\section{REFERENCES}

1 Feng D, Su S, Yang Y, et al. Job satisfaction mediates subjective social status and turnover intention among Chinese nurses. Nurs Health Sci 2017;19:388-92.

2 Marć M, Bartosiewicz A, Burzyńska J, et al. A nursing shortage - a prospect of global and local policies. Int Nurs Rev 2019;66:9-16.

3 Wang E. Requests for cesarean deliveries: the politics of labor pain and pain relief in Shanghai, China. Soc Sci Med 2017;173:1-8.

$4 \mathrm{Li} \mathrm{X}, \mathrm{Lu} \mathrm{J}, \mathrm{Hu} \mathrm{S}$, et al. The primary health-care system in China. The Lancet 2017:390:2584-94.

5 Li H, Yuan B, Wang D, et al. Motivating factors on performance of primary care workers in China: a systematic review and metaanalysis. BMJ Open 2019;9:e28619.

$6 \mathrm{Du}$ Q, Li Y, Shi Z. Application of performance management in the nurses overall quality of quantitative management. Chin J Mod Nurs 2013;19:3407-9.

7 Meyer JP, Allen NJ. A three-component model conceptualization of organizational commitment. Hum Resour Manag Rev 1991;78:61-89.

8 Lee YH, Chelladurai P. Emotional intelligence, emotional labor, coach burnout, job satisfaction, and turnover intention in sport leadership. Eur Sport Manag Q 2018;18:393-412.

9 Sousa-Poza A, Henneberger F. Analyzing job mobility with job turnover intentions: an international comparative study. J Econ Issues 2004;38:113-37.

10 Amponsah-Tawiah K, Annor F, Arthur BG. Linking commuting stress to job satisfaction and turnover intention: the mediating role of burnout. J Workplace Behav Health 2016;31:104-23.
11 Yang LF, Liu JY, Liu YH. Job burnout and turnover intention among nurses in China:the mediating effects of positive emotion. Chin Nurs Res 2018;5:43-7.

12 Hong E, Lee YS. The mediating effect of emotional intelligence between emotional labour, job stress, burnout and nurses' turnover intention. Int J Nurs Pract 2016;22:625-32.

13 Ye HL, Chelladurai P. Emotional intelligence, emotional labor, coach burnout, job satisfaction, and turnover intention in sport leadership. Eur Sport Manag Q 2017:1-20.

14 Pavlakis A, Raftopoulos V, Theodorou M. Burnout syndrome in Cypriot physiotherapists: a national survey. BMC Health Serv Res 2010;10:1-8.

15 Pines AM. Marriage burnout: a new conceptual framework for working with couples. Psychother Private Pract 1987;5:31-44.

16 Kroll HR, Macaulay T, Jesse M. A preliminary survey examining predictors of burnout in pain medicine physicians in the United States. Pain Physician 2016;19:E689.

17 Wong CA, Spence Laschinger HK, Laschinger HKS. The influence of frontline manager job strain on burnout, commitment and turnover intention: a cross-sectional study. Int J Nurs Stud 2015;52:1824-33.

18 Lu ACC, Gursoy D. Impact of job burnout on satisfaction and turnover intention: do generational differences matter? J Hosp Tour Res 2016;40:210-35

19 Samadi Miarkolaei H, Samadi Miarkolaei H. An investigation on relationship between employees' job satisfaction and organizational commitment. Manag Sci Lett 2014;4:669-78.

20 Aldrees T, Al-Eissa S, Badri M, et al. Physician job satisfaction in Saudi Arabia: insights from a tertiary hospital survey. Ann Saudi Med 2015;35:210-3.

21 Weiss DJ, Dawis RV, England GWManual for the Minnesota satisfaction question. 22. The University of Minnesota Press, 1967.

22 Tsounis A, Sarafis P, Andreas T. Validity and reliability of the Greek translation of the job satisfaction survey (JSS). BMC Psychol 2018;6:27.

23 Lopes S, Chambel MJ, Castanheira F, et al. Measuring job satisfaction in Portuguese military Sergeants and officers: validation of the job descriptive index and the job in general scale. Mil Psychol 2015;27:52-63.

24 Schutte N, Toppinen S, Kalimo R, et al. The factorial validity of the Maslach burnout Inventory-General survey (MBI-GS) across occupational groups and nations. J Occup Organ Psychol 2000;73:53-66.

25 Bothma CFC, Roodt G. The validation of the turnover intention scale. SA J Hum Resour Manag 2013;11.

26 Gan Y, Jiang H, Li L, et al. Prevalence of burnout and associated factors among general practitioners in Hubei, China: a crosssectional study. BMC Public Health 2019;19:1607.

27 Mao Y, He R, Liu J, et al. Turnover intention of primary health workers in China: a systematic review. The Lancet 2018;392:S17.

28 Lubbadeh T. Job burnout: a general literature review. Int Rev Manag Mark 2020;10:7-15.

29 Coomber B, Barriball KL, Louise Barriball K. Impact of job satisfaction components on intent to leave and turnover for hospitalbased nurses: a review of the research literature. Int J Nurs Stud 2007;44:297-314.

30 Chen I-H, Brown R, Bowers BJ, et al. Work-to-family conflict as a mediator of the relationship between job satisfaction and turnover intention. J Adv Nurs 2015;71:2350-63.

31 Zhou XD, Li L, Hesketh T. Health system reform in rural China: voices of healthworkers and service-users. Soc Sci Med 2014;117:134-41.

$32 \mathrm{Li} \mathrm{H}$, Yin GY. Discussion on the human resource management of public hospitals under the implementation of the new medical reform. Chin Med Herald 2012;9:161-3.

33 Yaylali E, Farnham PG, Schneider KL, et al. From theory to practice: implementation of a resource allocation model in health departments. J Public Health Manag Pract 2016;22:567.

$34 \mathrm{Li} \mathrm{J}$, Feng RH, Cui Y, et al. Comparison and Enlightment on health staff, income in typical countries under different economic development. Chin Health Econ 2013;32:91-3.

35 You J. Research on the current situation and improvement strategy of medical personnel salary level in China. Chin Health Econ 2018;37:17-21. 